\title{
PLANO PRÉ-FORMATADO PARA UM GÊNERO
}

\author{
Evandro de Melo Catelão* \\ Universidade Tecnológica Federal do Paraná \\ Departamento de Linguagem e Comunicação \\ Curitiba, PR, Brasil
}

\author{
Mônica Magalhães Cavalcante ${ }^{* \star}$ \\ Universidade Federal do Ceará \\ Departamento de Letras Vernáculas \\ Fortaleza, CE, Brasil
}

\begin{abstract}
Resumo: A noção de plano de texto (PT) é rediscutida neste estudo com o objetivo de propor considerações que contribuam para as formas de caracterização dos PT em análises de gêneros de formatos mais estáveis. Nossas reflexões (teórico/metodológicas) incidem sobre o que poderia distinguir, por meio de outro olhar, um PT fixo (PTF) e um PT ocasional (PTO). Indagamos se não seria mais apropriado verificar a dominância prototípica do gênero, tratando-a como um plano pré-formatado $(P P F)$. Para tanto, retomamos as análises de ligações sequenciais realizadas por Adam (2011; 2017), usando fábulas como exemplo. Dados da análise permitiram a determinação de uma ferramenta, mais abrangente em termos de reconhecimento de prototipicidade, reforçando nossa hipótese de que a noção de PT tem ampla relação com a natureza composicional dos gêneros. A observação do corpus pelo PPF possibilitou obter um esquema que contempla os três elementos que caracterizam os gêneros (tema, estilo e forma de composição).
\end{abstract}

Palavras-chave: Análise textual/discursiva. Plano de texto. Plano pré-formatado. Fábula.

\section{INTRODUÇÃO}

Este estudo retoma, face ao prolongamento em pesquisa de doutorado, parte da discussão delineada por Jean-Michel Adam para sua definição de plano de texto (PT). A ampla pesquisa do autor (dedicada, em sua maioria, à abordagem textual/discursiva ATD - do texto) trouxe conceitos que hoje têm sido usados pela Linguística Textual no Brasil e discutidos por diferentes autores (JURACH, 2015; WACHOWICZ, 2010; MARCUSCHI, 2005, 2008) (seja para redimensioná-los, seja para incorporá-los a suas pesquisas). A noção de sequência (ADAM, 1997), por exemplo, proporcionou uma visão do texto por limites composicionais, contribuindo para uma delimitação entre fronteiras

\footnotetext{
* Doutor em Letras pela Universidade Federal do Paraná. Professor em cursos de graduação e no Mestrado Profissional em Ensino de Ciências Humanas, Sociais e da Natureza na UTFPR. E-mail: evandrocatelao@gmail.com

** Doutora em Linguística pela Universidade Federal de Pernambuco, Professora do Curso de Graduação em Letras e do Programa de Pós-graduação em Linguística da Universidade Federal do Ceará - UFC. Email: monicamc02@gmail.com
} 
de análise (textual e discursiva) ${ }^{1}$, reduzindo o elevado número de tipologias em cinco sequências tipo (narrativa, descritiva, argumentativa, explicativa e dialogal). Esta nos parece ser a contribuição mais amplamente divulgada e trabalhada das propostas de Adam para os estudos em linguística do texto. Cremos que a visão composicional do texto e outros conceitos afins, ainda que bem menos discutidos, como a noção de plano textual, representam grandes possibilidades de utilização para novas considerações, se atentarmos para a ligação das sequências com unidades composicionais superiores e que estão após a fronteira textual - peritexto, como os gêneros (Figura 2). Com base nessa questão, pretendemos empreender uma discussão, no presente trabalho, que trate da relação plano de texto/gêneros de discurso, delineada com base em uma proposta de análise do gênero fábula, tendo em vista a noção que defenderemos de "plano pré-formatado para um gênero (PPF)".

Em sentido semelhante, Catelão (2013) adotou parcialmente, para a análise composicional de gêneros epistolares em sua tese, a subunidade de análise plano de texto proposta por Adam (2011, 2012; ADAM; BONHOMME, 2010). Como o objetivo da tese envolvia delinear as macroproposições de um protótipo básico de sequência argumentativa em cartas/bilhetes de suicidas, a discussão sobre plano de texto não se desenvolveu o suficiente, uma vez que o propósito no estudo era apenas relacionar o plano composicional do texto com a abordagem retórica da argumentação. Nesse momento, o autor observou, nas cartas analisadas, que a sequência argumentativa era, em geral, a dominante e que a finalidade persuasiva (na maior parte dos documentos) era descrever ou explicar que motivações redundariam no ato suicida em si. Como cartas de suicida, esse gênero parecia ter um plano de texto fixo. Mas, como a caracterização da noção de plano de texto, na proposta de Adam (2011), não se encontra tão desenvolvida quanto a da noção de sequência textual, muitas dúvidas restaram sobre essa subunidade de análise.

\section{Figura 1 - Esquema 30 de Adam}

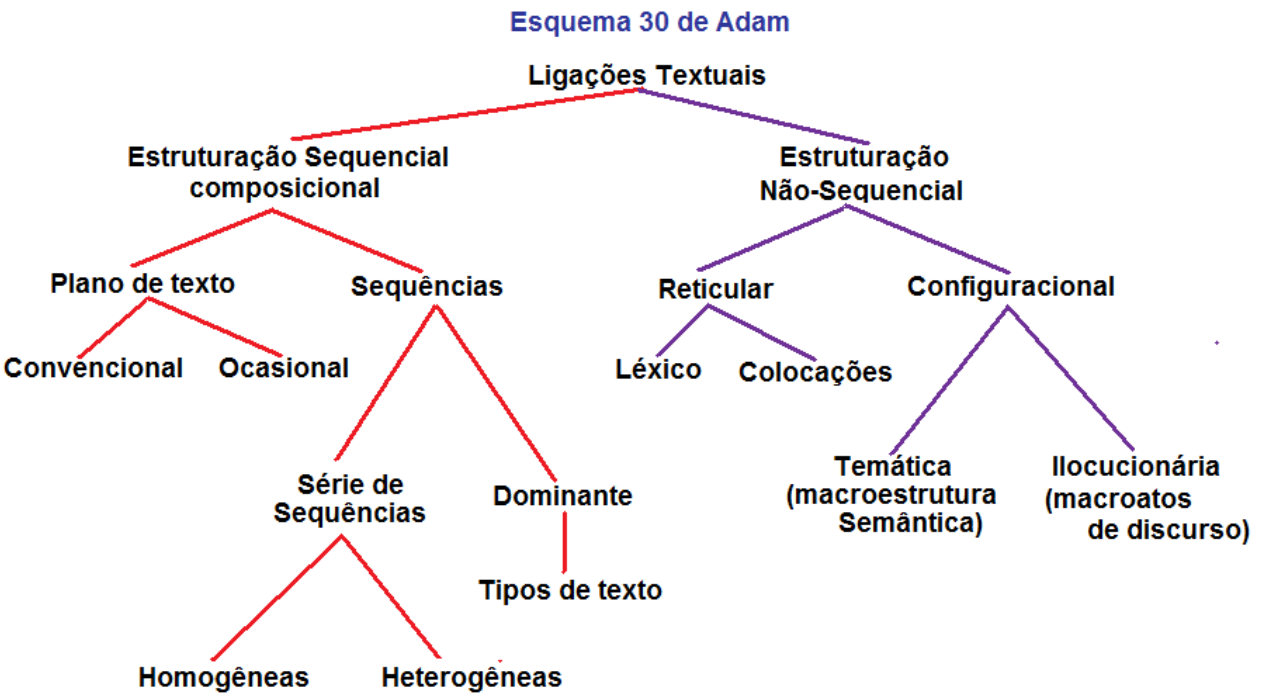

Fonte: ADAM (2011, p. 257).

\footnotetext{
${ }^{1}$ Para mais informações sobre a ATD e o modelo do autor, ver capítulo 1, Adam (2011).
} 
Assim, a definição de plano de texto (fundamental após o capítulo sobre as sequências em ADAM, 2011) parece-nos limitada ao que o autor denomina "ligações textuais" (esquema 30, Figura 1), sem muita exemplificação. Esta observação resvala no talvez cuidado do autor em propor que a heterogeneidade constitutiva dos textos aparece antes das regularidades, algo que o autor enfatiza ao tratar da definição de plano de texto na quarta edição de Les textes: types et prototypes, de 2017, obra que inaugurou a teoria das sequências em 1992.

Sobre essa complexidade constitutiva dos textos e as delimitações em planos de texto convencional e ocasional (ADAM, 2011; 2017), objetivamos refletir sobre os conceitos apresentados, discutindo-os com vistas a propor um tipo de delimitação que poderia contribuir para a caracterização da noção de plano de texto (convencional ou fixo) em gêneros mais “estáveis", por apresentarem ordenação estrutural com certa recorrência.

Destacamos também, entre a seleção de conceitos, a citação do autor, na obra de 2017, ao conceito bakhtiniano de gênero, enfatizando a consideração desse conceito no desenvolvimento da própria teoria do texto. A definição de texto e gênero, para o autor, contextualiza o lugar de um e de outro no plano de análise textual dos discursos (Figura 2). Para Adam (2017, p. 27), a mudança de paradigma da competência linguística dos sujeitos é guiada pela concepção de "tipos relativamente estáveis de enunciados". Refletindo sobre os pressupostos bakhtinianos, o autor descreve o contexto geral relativo aos gêneros, citando, por exemplo, as especificidades das esferas de circulação e seus próprios elementos configuracionais (tema, estilo). Partindo disso, o autor chega às suas próprias escolhas teóricas e terminológicas sobre "texto" e "gênero". O texto seria o traçado linguístico de uma interação social, a materialização semiótica de uma ação sóciohistórica dos usos, organizada por uma destas formas composicionais: a narração, a descrição, a argumentação, a explicação e o diálogo. Os gêneros seriam os padrões sociocomunicativos e sócio-históricos que os grupos sociais utilizam para dar relativa estabilidade a suas formas de usos textuais.

Na obra de Adam (2011), a exemplificação para o gênero epistolar dá margem para certa mobilidade em algumas partes do plano composicional da carta. Canonicamente, a carta apresenta abertura; exórdio; corpo da carta; peroração e fechamento. Por essa razão, o autor considera as partes de abertura, exórdio, peroração e fechamento como fazendo parte de um plano composicional fixo da carta. Havendo outros modos de organização composicional desse gênero, eles seriam tomados como planos de texto ocasionais. Nossas observações incidem sobre o que, de fato, distingue um plano de texto fixo e um plano de texto ocasional. Indagamos se não seria mais apropriado verificar a dominância prototípica do gênero, tal como se procede com a noção de sequência textual. Por fim, perguntamos se a concepção de plano de texto não poderia ser mais adequadamente tratada como plano de "gênero", se considerado o gênero, do ponto de vista dialógico, como uma tipificação de textos que apresentam certas regularidades de tema, composição e estilo nas práticas sociais em que costumam acontecer.

Nas definições de estruturação sequencial e não sequencial dos textos (esquema 30 de ADAM, 2011 - apresentado na Figura 1), alguns questionamentos podem ser levantados a partir da análise dos exemplos mencionados pelo autor. Na estruturação sequencial (composicional), por exemplo, Adam não esclarece se haveria recorrência (e, 
havendo, não explica como se daria) de marcas ocasionais dentro de um plano textual fixo (PTF) em outros gêneros além da carta.

Se relacionássemos a noção de plano textual, como o próprio autor sugere em seu modelo, à noção de gênero do discurso, deveríamos considerar, primeiro, por uma questão de coerência com a definição de gênero, a situação sociodiscursiva - como bem observam Rojo e Barbosa (2015) - e as marcas pragmáticas dessa situação, além das intenções discursivas para a escritura do texto.

Em uma fábula, por exemplo, seguindo o exemplo dado pelo próprio autor, o que determinaria a classificação de um plano de texto como fixo (PTF) ou ocasional (PTO)? Seu formato predominantemente narrativo (sequência narrativa como matriz) com vistas a uma lição moral, ou a intenção do autor em transfigurá-la em um poema em prosa? Essas são as perguntas que pretendemos neste artigo tentar, se não responder, pelo menos discutir, ao retomarmos as análises realizadas por Adam (2011) relativas às ligações sequenciais por sucessão.

Partindo desses pontos, organizamos uma discussão da aplicação da definição de plano de texto tal como delineada por Adam (2011), mas direcionamos o foco de nossas considerações para aspectos organizacionais dos gêneros de discurso com base nos traços de tema, composição e estilo . Neste artigo, iniciaremos por descrições de Adam (2011) da estrutura sequencial composicional (plano de texto e sequência) e acrescentaremos exemplos próprios na tentativa de ampliar os campos de análise e ponderar sobre os pressupostos da noção de gênero do discurso sustentada por Bakhtin. Na sequência, discutiremos a noção de plano pré-formatados para um gênero, ampliada pelo autor em Adam (2017).

\section{OPERAÇÕES DE TEXTUALIZAÇÃO: UNIDADE TEXTUAL ELEMENTAR, LUGAR DAS SEQUÊNCIAS E DO PLANO DE TEXTO}

Bem delineado, o modelo analítico de Adam (2011) traz uma configuração estrutural e conceitual extensa e com denominação híbrida no sentido de abarcar nomenclaturas e conceitos provenientes principalmente da retórica e da pragmática alinhados à $\mathrm{ATD}^{2}$. Como o objetivo deste trabalho é tratar de parte desses conceitos, em especial os relacionados a aspectos composicionais do texto, revisitamos os esquemas de análise do autor que tratam dos elementos composicionais de base, iniciando pela unidade textual elementar (proposição-enunciado) e tratando dos conceitos de período e de sequência.

A primeira consideração concerne às operações de textualização que marcam os espaços de segmentação do texto, da unidade mais simples (palavra) às unidades mais complexas do espaço que o autor reserva à Linguística Textual, parte direita do esquema da Figura 2:

\footnotetext{
${ }^{2} \mathrm{O}$ autor propõe o que chama de uma Linguística Textual desvencilhada de uma gramática de texto, utilizando-se da análise de discurso (emancipada da Análise do Discurso francesa) como fonte para suas análises.
} 
Figura 2 - Espaço dos campos textual e discursivo

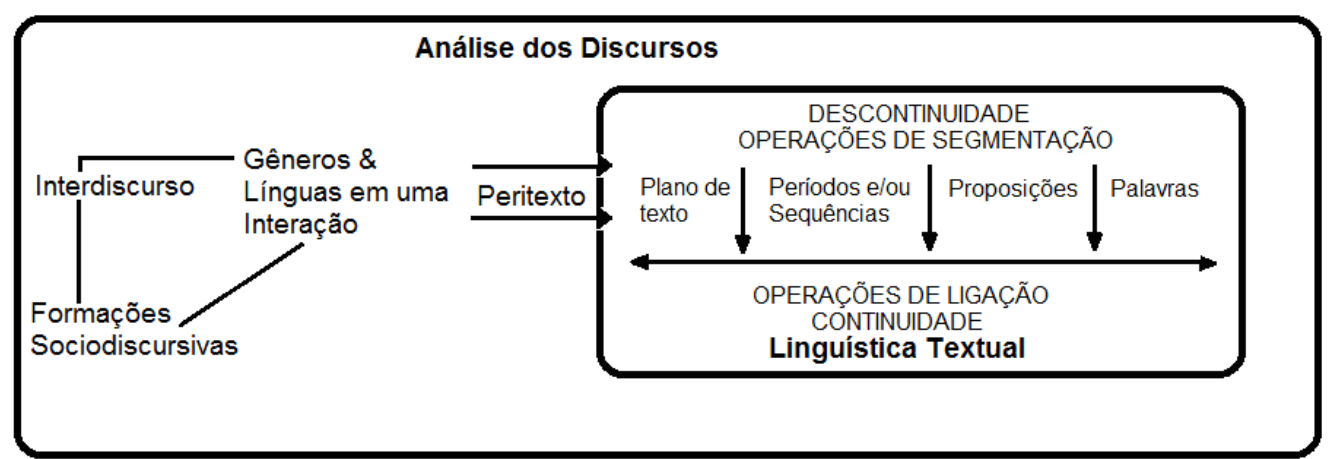

Fonte: Adam (2011, p.43)

Adam (2011) contempla no esquema a necessidade de demarcar níveis ou planos de análise da ATD, de um lado para a análise de discurso e, de outro, para a análise textual. No campo da LT, as operações de textualização seguem pela segmentação (palavras, proposições enunciadas, etc.) e pela ligação (construção de unidades semânticas pelas quais se reconhecem segmentos textuais). Nesse sentido, o autor delimita também, para o mesmo esquema, os níveis ou planos da análise textual (campo da LT) como sendo: o nível 1 com avaliação da textura - proposições enunciadas e períodos; o nível 2, da estrutura composicional, com a avaliação sequencial e do plano de texto; o nível $3 \mathrm{com}$ a avaliação semântica sobre a representação discursiva; o nível 4 com a avaliação da enunciação pela consideração da responsabilidade enunciativa e da coesão polifônica e, por fim, o nível 5 com os atos de discurso e a análise da orientação argumentativa. Para nossa discussão, interessa esclarecer os níveis 1 e 2.

Segundo as descrições do autor, o nível da textura remete eventualmente ao conceito de proposição-enunciado. Esse conceito leva em conta a adoção de um posicionamento textual e ao mesmo tempo discursivo, além de aspectos inerentes aos gêneros. Adam (2011) se preocupa, ao admitir essa denominação, em não utilizar expressões como frases, períodos, cláusulas para não correr o risco de entrar em outras áreas e acabar se perdendo em aspectos eminentemente estruturais. Assim, apresenta um termo que, para ele, corresponderia à unidade textual de base elementar, sem incorrer em contradições terminológicas, para ser coerente com o que propõe como uma Análise Textual dos Discursos (ATD). O termo proposição-enunciado representa para o autor essa unidade textual elementar, na medida em que também comporta um direcionamento enunciativo preponderante às análises textuais. "Ao escolher falar de proposiçãoenunciado, não definimos uma unidade tão virtual como a proposição dos lógicos ou a dos gramáticos, mas uma unidade textual de base, efetivamente realizada e produzida por um ato de enunciação, portanto, como um enunciado mínimo" (ADAM, 2011, p.107).

O termo proposição-enunciado corresponde, para Adam (2011), à denominação mais adequada para o tratamento de uma unidade de análise textual segundo os postulados atuais da Linguística Textual. A esse respeito, o autor tem uma longa descrição que visa caracterizar por que a utilização de termos como frase ou proposição não seria adequada: para ele, esses termos trazem historicamente em si uma definição limitada e imprecisa. A 
definição de período, por outro lado, não é descartada, mas recebe uma ressignificação (como veremos a seguir) dentro das células de construção do texto. Adam (2011, p.106) alega a necessidade de uma unidade textual mínima, metalinguisticamente adequada "à natureza do produto de uma enunciação (enunciado)" somada à "designação de uma microunidade sintático-semântica" (proposição) ${ }^{3}$. Essa delimitação serve, portanto, para marcar uma referência ao produto de um ato de enunciação. Assim sendo, esse produto enunciativo convoca vários outros no momento da análise (quem, para quem etc.). Em resumo, analiticamente, a noção de proposição-enunciado serve para marcar que a unidade textual mínima carrega ligação com cotexto anterior e posterior além de três dimensões complementares: responsabilidade enunciativa (ponto de vista - quem e o que é dito); referência como representação discursiva (conteúdo proposicional); valor ilocucionário (potencialidade argumentativa do enunciado), também ligados aos níveis 3, 4 e 5 da análise textual, descritos anteriormente. Como vimos no Esquema 1, o autor se preocupou em delimitar as bases analíticas, para estabelecer, com mais precisão, os espaços da linguística textual e da análise de discurso.

As proposições-enunciados tendem a agrupar-se, pelos processos de textualização, em duas unidades cada vez mais complexas: os períodos e as sequências. São esses, talvez, os conceitos mais peculiares à proposta de Adam e mais centrais, uma vez que operam como um ponto de partida para algumas análises textuais possíveis ${ }^{4}$ (CATELÃO, 2013; JURACH, 2015). Tanto o período como as sequências são compostos de agrupamentos particulares de proposições-enunciado, cada qual com características particulares.

De forma sucinta, podemos dizer que os períodos representam tipos de unidades (menores e mais simples que as sequências. Trata-se de unidades menos complexas que as sequências e de estrutura não muito marcada, por isso difícil de ser mensurada em relação às sequências. Exemplificando os períodos, Adam (2008, p. 374, grifos do autor) afirma que eles

\begin{abstract}
resultam das mais variadas formas principais de ligações: as ligações rítmicas de proposições (por retomadas de fonemas/grafemas, lexemas, sintagmas inteiros), as ligações léxico-semânticas (paralelismos, quiasmas, antíteses), as ligações por conexão (asseguradas por conectores). Dois tipos de pacotes de proposições devem ser considerados: os empacotamentos não (ou fragilmente) moldados, que formam simples períodos, e os empacotamentos sob a forma de macroproposições, que entram na constituição das sequências.
\end{abstract}

Existem, pois, dois tipos de "empacotamentos" como construtos formais possíveis para a organização de um texto: um menor e mais simples, de conexões simples entre proposições-enunciado, que constitui o período; outro maior e mais complexo, que envolve conjuntos de proposições-enunciado, agrupados em macroproposições, formando as sequências textuais.

\footnotetext{
${ }^{3} \mathrm{O}$ termo frase é utilizado somente para designar os limites assinalados por uma maiúscula e um ponto, ou seja, sua dimensão projetiva (ADAM, 2011, p.107).

${ }^{4}$ Adam (2011), no entanto, separa no plano da análise textual a noção de período para o nível 1, junto com a de proposição, mas une período e sequência para descrever as unidades de crescente complexidade.
} 
Nessa teia de relações, as sequências seriam unidades textuais mais complexas, compostas de macroproposições com propriedades específicas de ligação com outras macroproposições. As sequências estão organizadas em redes relacionais e hierárquicas cujas partes (macroprosições) podem ser identificadas e decompostas em razão de serem também relativamente autônomas, mas ligadas internamente. As relações se dão, portanto, tanto entre proposições-enunciado dentro de uma macroproposição, quanto entre as macroproposições em si, como entre elas e o todo da sequência textual.

Adam (2011) enfatiza que um texto pode se constituir a partir de uma sequência dominante e de várias sequências diferentes nela inseridas. Essa relação complexa e heterogênea é fortemente influenciada por aspectos singulares de cada gênero em que se enquadra o texto. Assim, qualquer que seja o gênero, um texto é composto por segmentos de diferentes sequências, os quais permitem observar as regularidades de organização textual, reconhecíveis, por vezes, por uma série de marcações linguísticas.

As sequências não constituem uma ampla estruturação frástica, aumentada a partir de unidades microtextuais. Trata-se de uma estrutura relacional pré-formatada, intermediária entre as unidades sintáticas e o plano do gênero, uma espécie de "esquema de texto", concebido num nível macrotextual. Compete ao linguista do texto descrever esse nível intermediário sem deixar de atentar nem para as restrições sintáticas, nem para as determinações do gênero do discurso.

Assim, as próprias macroproposições que entram na composição de uma dada sequência dependem de pré-combinações provenientes das macroações sociodiscursivas: narrar, descrever, argumentar e explicar (recorrentes e dominadas precocemente pelas pessoas). Dito de outra forma, as sequências textuais são, em sua gênese, fruto de nossas capacidades (cognitivas e pragmáticas) mais fundamentais e coocorrem em nossas ações interpessoais, sendo memorizadas por impregnação cultural. Nas palavras do autor, as diferentes combinações 'narrativa', 'argumentativa', 'explicativa' e 'descritiva' são atos de discurso não primitivos ${ }^{5}$, intermediários entre o objetivo primário de uma asserção (partilhar uma crença) e o objetivo último (convencer a fazer).

Complementando o grupo de sequências, o 'diálogo' estaria em regime próximo aos atos não primitivos. O diálogo, marcado como um ato primitivo, articularia atos de força primária por ter uma posição, dita pelo autor, particular em relação às outras sequências e/ou macroações sociodiscursivas (narrativa, argumentativa, explicativa e descritiva). Isso é importante, pois, nesse jogo de atos entre as práticas discursivas orais e escritas, "em uma situação oral, o modo composicional dialogal-conversacional estende sua hegemonia sobre todos os outros modos de composição" (ADAM, 2011, p. 253). Isso acontece porque oralmente construímos o contexto necessário ao entendimento do discurso e temos ali representadas as figuras de intercâmbio. Para os textos escritos, criase o que se denomina ambiente transacional para uma sequência dialogal elementar, idealizada com base no encadeamento de réplicas das personagens.

\footnotetext{
${ }^{5} \mathrm{O}$ autor alerta que as teorias clássicas dos atos de discurso não permitem uma descrição das macroações sociodiscursivas (narrar, descrever, argumentar e explicar), discutidas na formulação da noção de sequências.
} 
O autor chega, assim, às cinco sequências de base correspondentes às cinco relações macrossemânticas memorizadas por impregnação cultural ${ }^{6}$ - dialogal, argumentativa, descritiva, explicativa e narrativa.

\section{PLANO OU PLANOS DE TEXTO}

O lugar do plano de texto (PT) na proposta da ATD é imediatamente posterior ao dos períodos e das sequências e anterior à fronteira entre o texto e o discurso, como pode ser observado na Figura 2. A mera observação do esquema já permite ver indícios de que as características definidoras da noção de plano de texto estariam situadas entre as sequências e/ou períodos e o plano discursivo onde aparecem os gêneros. Todavia, a caracterização dessa unidade de análise plano de texto não se faz de maneira muito precisa na proposta do autor.

Para Adam (2011), "o reconhecimento do texto como um todo passa pela percepção de um plano de texto, com suas partes constituídas, ou não, por sequências identificáveis" (ADAM, 2011, p. 254), ou seja, a visão do todo é inseparável da compreensão das partes, o que significa reconhecer a existência de uma unidade composicional maior do que a sequência textual, isto é, um plano de texto. Um plano de texto corresponderia, então, a um conjunto organizado de enunciados, estes dispostos e hierarquizados segundo parâmetros historicamente determinados.

Dessa visão de constituição do texto, podemos supor que os aspectos norteadores dos próprios gêneros podem influenciar o plano de texto classificado como fixo. Isso reforça nossa hipótese de que a noção de plano de texto tem relação com a natureza composicional do gênero do discurso. No entanto, a classificação de plano de texto ocasional, pelo modo como é discutida pelo autor, não parece opor-se a plano de texto fixo, e nisso parece residir a grande confusão ou imprecisão em torno do que seja um plano de texto.

Pela teoria das sequências ${ }^{7}$, seria possível inferir que: a) um/o texto, em termos composicionais, é composto de sequências (uma ou várias sequências e/ou períodos); b) aspectos internos aos gêneros (de ordenação social e individual tendo em vista o enunciador) de discurso podem trazer indícios da recorrência com que uma dada sequência pode ser utilizada; c) formatos textuais que apresentem "certa recorrência" podem comportar em suas bases sequências pré-definidas pelo uso social.

Cumpre salientar que, para Adam, analisar um texto como um todo implica considerar também sua unidade configuracional (o contexto semântico e o pragmático). É por isso que, para o autor, dois tipos de operação fazem do texto um todo configurado: a unidade temática global (semântica) e a unidade ilocucionária (pragmática). Restam, no

\footnotetext{
${ }^{6}$ Adam (2011, p.208) afirma que na instrução-injunção “as formas de textualização variam bastante em função dos gêneros de incitação à ação", não considerando a injunção uma sequência, justamente por não ser possível caracterizar um padrão na mesma direção das outras cinco sequências.

${ }^{7}$ Para Adam (2011), as unidades composicionais de base para os textos têm principalmente as cinco sequências como possibilidades de ligação (somadas a outros tipos de proposições/enunciados - períodos) para se chegar às diferentes materialidades de texto, denominadas gêneros no campo discursivo.
} 
entanto, algumas lacunas no esquema 30 (cf. ADAM, 2011, p. 255), que reproduzimos a seguir (com marcações nossas). Vê-se que as ligações seriam primariamente divididas em dois universos textuais: estruturação sequencial (partes do texto e visão composicional) e não sequencial (sentidos do texto - configuração).

\section{Figura 3 - Ligações textuais ${ }^{8}$}

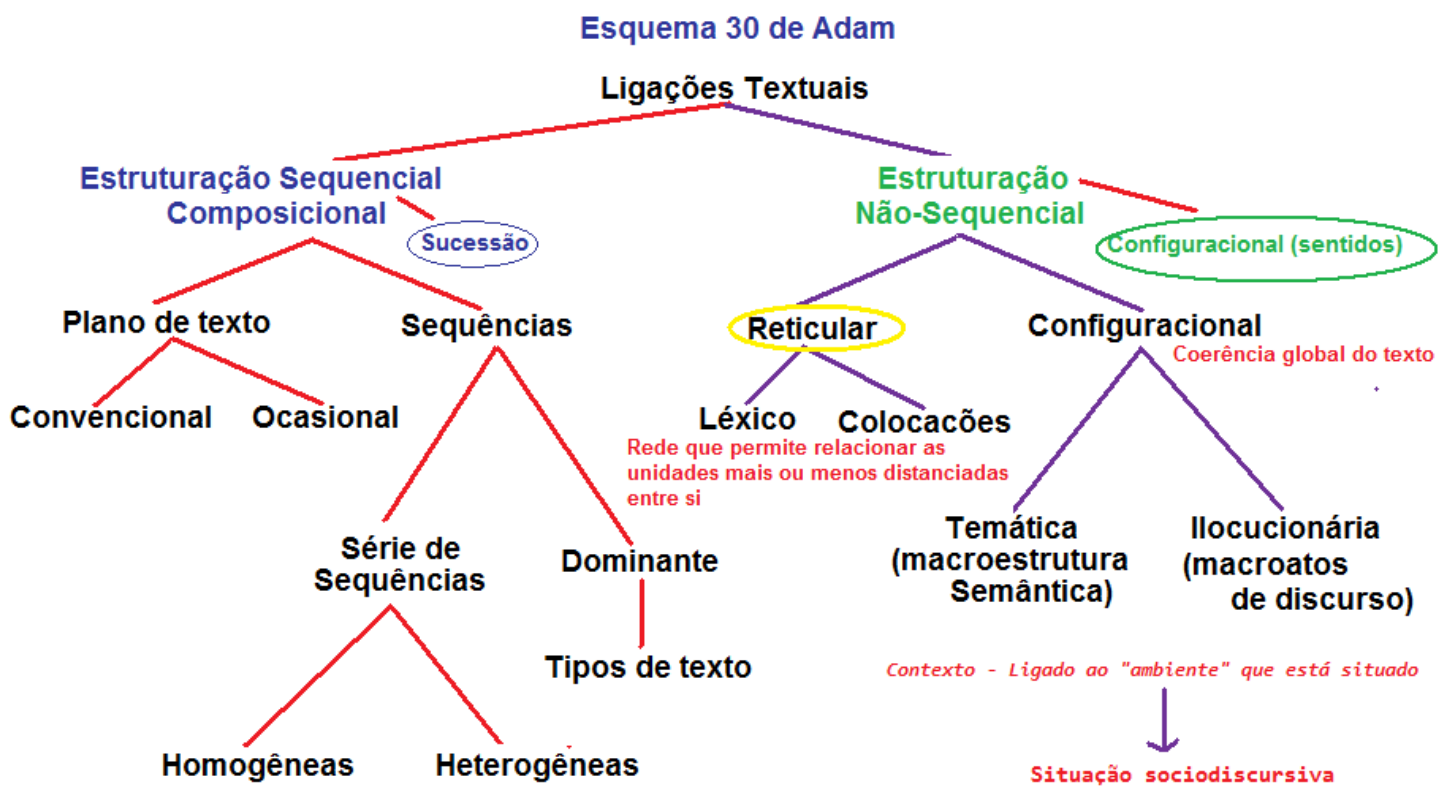

Pelo esquema, vê-se que, nos componentes da estrutura sequencial composicional, o plano de texto aparece na mesma linha da aplicação sequencial de base. Primeiramente, Adam (2011) afirma que o plano de texto (PT) desempenha papel essencial na composição macrotextual do sentido. Sua definição de PT leva em conta o modelo retórico do plano da disposição e, portanto, a nosso ver, assenta em aspectos organizacionais do texto, ainda que associados a pressupostos pragmáticos de unidades retóricas.

Adam (2011) apresenta apenas uma definição analítica de plano de texto, ponderando sobre a hipótese de que as marcas composicionais e o estatuto histórico dos gêneros determinariam os planos de texto convencionais ou fixos (PTF) e os planos de texto ocasionais (PTO). Essa classificação permite pensar em categorias de texto, contudo, de forma não muito clara ou pré-identificável como nos protótipos das sequências, conforme demonstraremos nas aplicações na seção a seguir.

Adam (2011) afirma que o PTF seria estabelecido ou previsto pelos gêneros de discurso de forma total ou parcial, já no PTO não haveria essa previsão, pois ele seria reinventado, como uma espécie de decisão individual. Acreditamos que, por esse ponto de vista, não existia oposição entre plano de texto fixo e plano de texto ocasional, pois ambos seriam considerados no momento de elaboração de um texto.

\footnotetext{
${ }^{8} \mathrm{O}$ termo ligações textuais é utilizado como forma de exemplificação pelo autor presente na relação entre as questões de sentido (estrutura não-sequencial) e elementos puramente composicionais (estrutura sequencial).
} 
O presente trabalho converge para a reivindicação de que a noção de plano de texto fixo seja necessariamente relacionada às práticas convencionais de gêneros (plano préformatado para um gênero - PPF), pois contempla os aspectos da estrutura composicional, do tema e do estilo dos gêneros naturalmente reconhecíveis e, portanto, previsíveis. Dependendo da rigidez do gênero do discurso, determinada pelas convenções sociais, o PPF de gênero será mais "fixo", ou mais prototípico. Certos gêneros, como os do domínio discursivo publicitário e alguns do domínio literário, por exemplo, permitem ao locutor maior liberdade de decisão sobre seu plano de texto individual, ou "ocasional". Falaríamos, dessa forma, em traços mais, ou menos, prototípicos, não em uma oposição entre planos de texto fixos e ocasionais. O que é mais ou menos fixo ou relativamente estável é o que convencionalmente se espera em um gênero da tríade tema-composiçãoestilo. Assim sendo, optamos por reservar à etiqueta "plano de texto ocasional" uma decisão individual sobre os arranjos composicionais, temáticos e estilísticos que um determinado plano pré-formatado (ou fixo) do gênero comportasse.

Nem todo texto é necessariamente composto por estruturas ordenadas ou fixas de sequências. O texto de um dado gênero pode ter uma estrutura bastante flexível, sendo, muitas vezes, os elementos pragmáticos os responsáveis pela opção por uma estrutura linear convencional ou por um percurso com encadeamento textual totalmente ocasional. Esse aspecto pode ser ilustrado pelos gêneros publicitários, que parecem permitir um encadeamento diversificado. Além deles, os gêneros literários trazem bons exemplos de alta maleabilidade: poemas, como o soneto, podem apresentar formatos fixos, porém, outros formatos de poema lírico não seguem nenhuma regra e podem afastar-se criativamente de uma estrutura prototípica de poema.

As diferentes situações sociodiscursivas guiam (e ao mesmo tempo são guiadas por) tipos relativamente estáveis de textos, os gêneros. Os planos pré-formatados dos gêneros são convencionalmente construídos e também descontruídos ou reconstruídos pelo interlocutor de formas variadas. A pressão pragmática é tão importante para essa reconstrução que pode nos levar a seguir exatamente um "protótipo" estruturalmente prédefinido. Certos gêneros são mais resistentes a mudanças estruturais, devido ao tipo de prática social a que estão associados, como é o caso de alguns gêneros das esferas acadêmica, jornalística, jurídica entre outras. Por outro lado, encontramos comumente outros casos em que esses planos pré-formatados são alterados (também intencionalmente) para formas inesperadas (mesmo sendo consideradas do mesmo gênero) para assim se adequarem a outro tipo de interlocução, justamente com o objetivo de marcar uma intenção singular. Essas alterações, evidentemente, só são possíveis, sem levar à estranheza, porque as próprias convenções composicionais, temáticas e estilísticas do gênero do discurso permitem isso.

Nesses limites, vistos composicionalmente, planos de texto fixos apresentam justamente a facilidade de servirem como "modelos" de produção, que nos orientam (ou não) a usá-los, tendo em vista situações que demandam objetividade, clareza, ponderação como alguns gêneros acadêmicos (resenha, artigo científico). Em outros domínios discursivos (principalmente no espaço escolar), os textos com traços mais prototípicos de um dado gênero contribuem simplesmente para atividades que têm por objetivo observar se conhecemos estruturalmente um gênero e/ou se somos capazes de reproduzi-lo. Em 
síntese, os PTF podem ser caracterizados como formatos socialmente cristalizados pelo uso, nas palavras de Adam (2011), textos que apresentam algumas constantes composicionais. Acrescentamos que aspectos temáticos e estilísticos também se tornam padrões relativamente estáveis nas práticas discursivas que se estabilizam parcialmente ao longo do tempo.

Para ilustrar, mencionamos o mesmo exemplo do autor relativo a gêneros epistolares. A carta, por exemplo, apresenta, segundo o autor, apesar da ampla variedade, constantes composicionais que marcam a abertura/exórdio e peroração/fechamento (semelhantes aos textos dialogais-conversacionais). O corpo da carta, por outro lado, mostra-se livre e atende tão-somente às intenções do produtor, podendo seguir com um relato (sequência narrativa e descritiva), ou com a busca ou expressão de uma tese (sequência argumentativa). Na mesma direção, gêneros poéticos como os sonetos também são delineados pelo autor como exemplos de plano de texto fixo. A estruturação com dois quartetos e dois tercetos, a métrica e a identificação por rimas dão ao gênero uma planificação canônica.

Propomos que as relações a serem consideradas no nível do PTF não são planificadas tendo em vista apenas a estrutura composicional das sequências. Pensamos que a noção de plano de texto fixo mantém uma inter-relação estreita com aspectos ligados aos gêneros do discurso. Inspirados em alguns traços que a teoria oferece, sugerimos um tipo de análise que examine mais de perto condições que alguns textos permitem.

\section{A NOÇÃO DE PLANO PRÉ-FORMATADO PARA UM GÊNERO - UM PLANO DE GÊNERO?}

Como destacado, o modelo analítico de Adam (2011) volta-se a uma dupla articulação entre o espaço da linguística textual e o da análise de discursos, contudo separa os campos de observação, deixando os gêneros fora do campo da LT e das relações de continuidade e segmentação, mesmo que em alguns momentos as noções composicionais resvalem para restrições dos gêneros do discurso.

A tentativa de aplicação do modelo do autor nos levou a considerar, por esse motivo, outra possibilidade analítica. Comungamos com a concepção de gêneros discursivos defendida por Rojo e Barbosa (2015), em uma perspectiva dialógica, para quem os gêneros devem ser observados na articulação entre aspectos composicionais e discursivos.

Para as autoras, a denominação "gêneros de discurso" vem da necessidade de tomar o texto como uma unidade comunicativa, encaixado em nossas atividades sociais estruturadas e dependentes de textos anteriores. Pela concepção bakhtinina, falamos e escrevemos por meio dos gêneros - "tipos relativamente estáveis de enunciados". O funcionamento dos gêneros está condicionado às nossas vidas cotidiana e pública, pois eles dão forma aos textos. Segundo as autoras, a definição de gênero está subordinada ao funcionamento social das diferentes instituições humanas (que elas associam à noção bakhtiniana de esferas). 
Assumindo tal pressuposto, recorreremos a um olhar dialógico para os gêneros para afirmar que a momentânea estabilidade de tema, estilo e forma de composição dos tipos de texto está ligada à noção bakhtiniana de esferas de atividade humana. Os diferentes modos de vida aparecem atrelados às diversas esferas/formações sociais que condicionam "tipos temáticos, composicionais e estilísticos de enunciados/textos relativamente estáveis - os gêneros" (ROJO; BARBOSA, 2015, p. 64).

As autoras, porém, consideram as esferas de atividade e esferas de comunicação como os dois primeiros passos metodológicos para uma análise dos gêneros. Entendemos isso como a necessidade de condicionar qualquer análise dos textos à situação sociodiscursiva, que, por sua vez, também determina a escolha e a utilização, mais flexível ou não, de determinado gênero em dadas esferas. As esferas estão relacionadas aos tipos de atividade humana que são nela desempenhados e aos gêneros que ali circulam em forma de textos/enunciados concretos. Assim, as características do gênero seriam determinadas pela finalidade, funcionamento e especificidade da esfera na qual ele circula, algo próximo ao que estabeleceremos na análise da fábula. Seguindo o recorte, ratificamos a necessidade de se atentar para os três elementos componentes dos gêneros sob a perspectiva de Bakhtin (1997): tema, estilo e forma de composição. Cremos que esses três aspectos são conciliáveis com as noções aqui defendidas.

Grosso modo, o tema (elemento mais importante do texto) corresponde ao conteúdo inferido somado a uma valoração do locutor, no contexto sócio-histórico em que ele se insere. No tema, evidentemente, há sempre um atravessamento ideológico, mas o sentido de um dado texto depende da apreciação de um dado interlocutor, em um dado momento de produção específico, por isso o texto é um enunciado único e irrepetível. Os sentidos que vão se repetindo, mas também se acumulando, são diferenciados por Volochinov/Bakhtin (1981) em dois tipos: tema do signo (acumulado) e tema da enunciação (pertencente a um momento histórico particular) (ROJO; BARBOSA, 2015).

O estilo, por sua vez, representa determinada ordem de traços organizados por escolhas linguísticas (lexicais ou estruturais). Fazemos essas escolhas no momento da concepção/produção do texto, sendo elas determinantes para a interpretação requerida. Um mesmo tema, por exemplo, pode ser apresentado em estilos diferentes para que possamos dizer o que realmente queremos dizer, ou seja, expressar nossa "vontade enunciativa", segundo as autoras.

Costa (2013, p.154) aponta alguns direcionamentos possíveis para uma análise do estilo nos gêneros por uma perspectiva discursiva. Nas pesquisas sobre estilo no Brasil, a autora cita basicamente duas linhas de estudo que correspondem ao embrião de duas tendências presentes em Bakhtin, uma "centrada na relação entre a norma e o desvio", "outra centrada na rigidez ou flexibilidade do estilo do gênero". Costa (2013) sugere uma análise da relação estilo e gênero realizada em três níveis: 1) dimensão social do estilo (estilo do gênero em Bakhtin), resultado da elaboração histórico-social, em que se observa uma associação estável entre determinadas formas linguísticas e os gêneros; 2) dimensão individual do estilo, advinda de escolhas linguísticas do locutor, que, por sua vez, toma como referência o estilo do gênero, já que as formas linguísticas já têm seus usos consolidados historicamente (estilo do texto); 3) dimensão que resulta do agrupamento de textos, atinente a estilo de autor, de época, de jornal etc., recorrentes em um conjunto de textos e sempre condicionados por determinações sócio-históricas. 
Nossa proposta se aproxima da proposta de análise da dimensão social do estilo, por observar aspectos recorrentes do gênero (mas reconhecendo que cada texto é único), principalmente em função de a noção de plano pré-formatado de texto estar relacionada à relativa estabilidade do gênero em temos de tema, estilo e composição.

Finalmente, o traço de composição representa a forma de acabamento do gênero e "está relacionado ao que a teoria textual chama de '(macro/super)estrutura' do texto, à progressão temática, à coerência e coesão do texto" (ROJO; BARBOSA, 2015, p.94). Esse último elemento organizacional dos gêneros discursivos é o que mais nos chama atenção, pois é dele que objetivamos partir para a denominação da possibilidade de existência de um/ou mais plano pré-formatado para um gênero. Essa denominação foi adotada por Adam (2017) e converge bem para a nossa proposta, pois distribui os gêneros conforme sua dominância composicional. Falar em plano pré-formatado nos parece mais adequado, por possibilitar mais de um plano genérico para um determinado conjunto de textos, o que é bastante condizente com a heterogeneidade constitutiva dos gêneros.

Embora Rojo e Barbosa (2015) entendam que a tentativa de uma prototipação dos gêneros leve, logo de partida, a inúmeros inconvenientes, dada a sua heterogeneidade composicional, não encampamos inteiramente essa visão, pois existem regularidades composicionais, como defende Adam (2017), que permitem aproximar os gêneros. Interessa-nos particularmente refletir sobre a relação entre os traços composicionais que denominaríamos como recorrentes dos gêneros e a noção de plano de texto fixo, ou plano pré-formatado de gênero.

De acordo com Adam (2017), é possível olhar para os gêneros não apenas como tipos de práticas discursivas que integram formações sociodiscursivas ou domínios (jornalístico, religioso, literário, acadêmico etc.), mas também considerá-los a partir de agenciamentos pré-formatados de proposições e macroproposições, classificáveis em cinco relações macrossemânticas básicas, adquiridas por impregnação cultural: narrativo, descritivo, argumentativo, explicativo e dialogal. Haveria, por esse prisma, gêneros do narrar, do descrever, do argumentar, do explicar e do dialogar. Essa possiblidade de agrupamento de gêneros por uma perspectiva composicional é o que, a nosso ver, pode tornar viável a relação indiscutível que existe entre sequência textual, plano de texto e gênero do discurso.

Sugerimos, a seguir, um esquema (figura 4) que sintetiza uma possibilidade de análise que contemple esses diferentes aspectos. Pelo esquema, a análise para um PPF partiria não de uma divisão entre os planos discursivo e textual, mas da tripla articulação entre tema, estilo e forma de composição. $\mathrm{O}$ aspecto macroestrutural do formato de composição não perderia a ligação com os outros dois elementos da tríade: tema e estilo, uma vez que no espaço dos gêneros um dependeria do outro. Nessa proposta, incluímos o conceito de plano de texto na linha de observação do plano de composição do gênero e, desse ponto, articulamos dois objetivos: 1) analisar o plano pré-formatado para um gênero; 2) observar elementos composicionais de um dado texto. $\mathrm{O}$ espaço dedicado à esfera pode remeter a um outro tipo de análise (que não é foco deste estudo) em que o PPF dialoga intertextualmente com outra esfera, como no caso de uma receita médica em forma de poema, por exemplo (MARCUSCHI, 2008). 
Figura 4 - Espaço do plano pré-formatado para um gênero

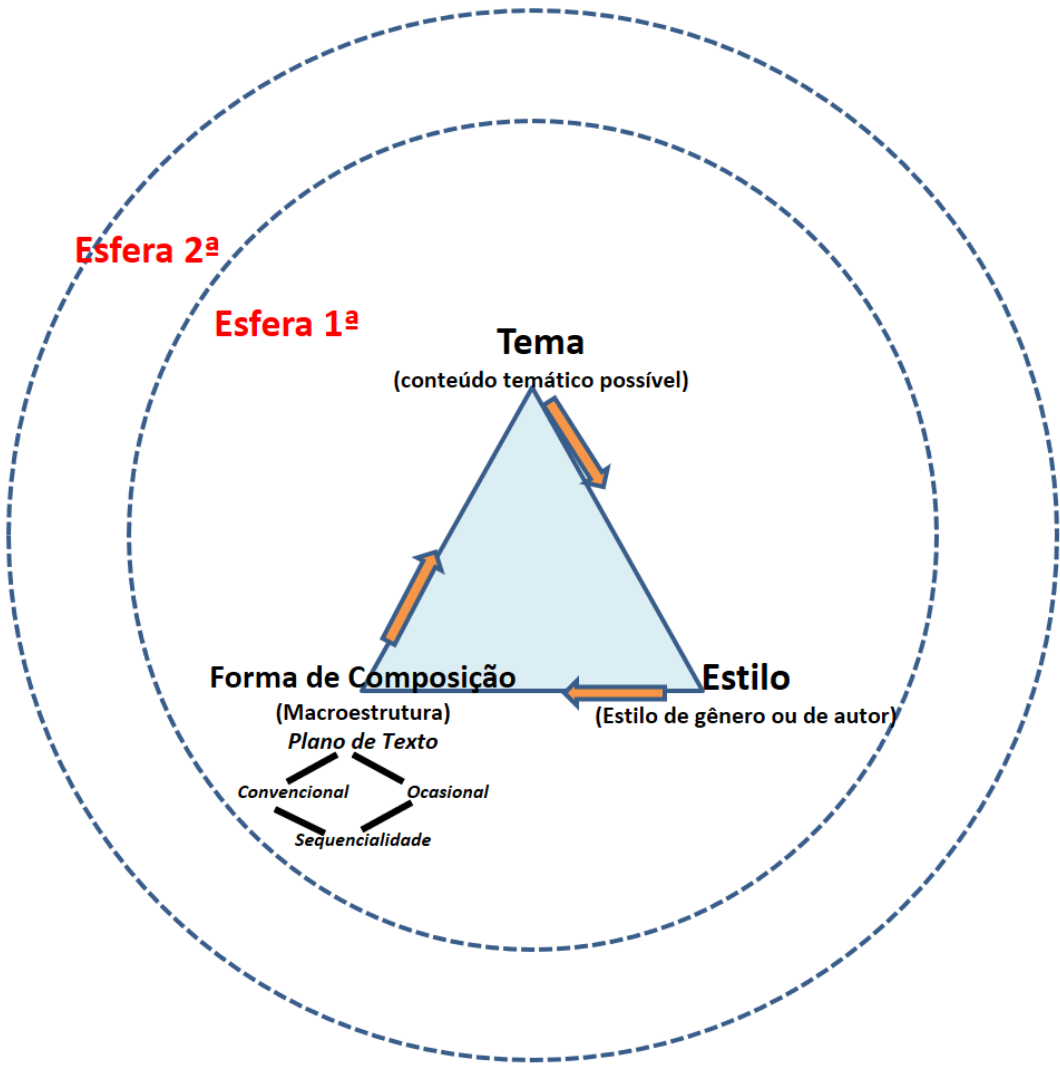

Com base nesse esquema, propomos uma reflexão sobre o gênero fábula, tendo como apoio um estudo sobre o gênero realizado por Portella (1983).

\section{ANÁLISE DE UM PPF PARA A FÁBULA}

Em sua esfera de circulação, a fábula é comumente caracterizada como um formato literário particular, que traz em seu interior uma narrativa breve, em prosa ou em verso, e cujos personagens são, via de regra, animais. Esse gênero encena uma lição, um princípio ético, político ou literário que se depreende facilmente - são as chamadas verdades gerais, inerentes à humanidade, à experiência de vida, à noção filosófica do bem e do mal (PORTELLA, 1983). Nossa questão preliminar para esse gênero seria qual tipo de descrição poderíamos tomar em função de uma caracterização do gênero pela tríade anteriormente apresentada para um PPF. Enfatizamos, na análise, as recorrências, não as peculiaridades de cada texto singular.

\section{T1}

\section{O desespero da Velha}

A velhinha encarquilhada ficou toda contente vendo aquela linda criança a quem todos faziam festa, a quem todos queriam agradar: aquele lindo ser, tão frágil como ela, a velhinha, e, também como ela, sem dentes e sem cabelos.

E aproximou-se, procurando dar risadinhas, com trejeitos gentis. 
Mas a criança, assustada, debatia-se sob as carícias da boa senhora decrépita, e enchia a casa com seus ganidos.

Então, a boa velha retirou-se para a sua eterna solidão, e chorava num canto, dizendo consigo:

- “Ah! Para nós, infelizes fêmeas velhas, já passou o tempo de agradar, mesmo aos inocentes, e causamos horror às criancinhas a quem queremos amar!

(ADAM, 2011, p. 263)

Começando pela consideração da noção de plano de texto, poderíamos afirmar que o plano de texto fixo desse gênero seriam as características temáticas, composicionais e estilísticas da fábula. Os chamados planos de texto ocasionais (PTO) são descritos na teoria como entidades que fogem dos padrões canônicos no momento de sua reconstrução na interpretação quando comparados com outros exemplares. Vejamos as justificativas apresentadas por Adam (2011) para um exemplo que condensa poema e fábula.

Para o autor, o exemplo reúne uma estrutura narrativa bem marcada, que, por outro lado, também apresenta unidades textuais geradoras de relações rítmicas próprias da prosa poética. Essa desestabilização do que se espera de uma fábula leva Adam a classificar esse texto como tendo um plano de texto ocasional (PTO), mesmo que a fábula encene um princípio ético, nesse caso, explícito, em que a avaliação final ou moralidade apareceria no discurso direto do último parágrafo (na fala da heroína sobre seu caso particular).

Pensemos, em primeiro lugar, sobre essa possível desestabilização do plano de texto fixo da fábula, que redunda numa organização particular do locutor em um plano de texto ocasional. Se admitirmos um PTO, teremos que pressupor que, em princípio, essa estrutura do exemplo não é recorrente ou é inesperada. Mas não nos parece o caso, pois encontramos na literatura diferentes exemplares de prosa poética para a fábula, o que representaria uma face prevista pelo estilo. Além disso, a própria definição do gênero fábula, conforme mostramos anteriormente, traduz essa possibilidade: "narração breve, em prosa ou em verso" (PORTELLA, 1983). Assim sendo, discordamos que esse seja um plano de texto ocasional apenas pela marcação de um ritmo.

Indo mais a fundo pela historicidade do gênero, para Portella (1983) a fábula exerceu, e exerce ainda hoje, força inerente à intenção discursiva do momento de produção, como o confirmam modelos de fábulas clássicas. Quando contada por Esopo, por exemplo, teve a finalidade de dar um conselho de vida; quando contada por Fedro, objetivou fazer crítica a alguém; já quando contada por La Fontaine visou ao divertimento e atendeu a efeitos poéticos grandiosos. Esse último caso teve na narrativa sua força dominante, e essa ênfase fez, segundo o autor, com que La Fontaine deixasse a moralidade ser deduzida pelo leitor na maioria dos casos, como pode ser observado em T2.

T2

A raposa e as uvas

Contam que certa raposa,

Andando muito esfaimada,

Viu roxos maduros cachos

Pendentes de alta latada, 
De bom grado os trincaria,

Mas sem lhes poder chegar.

Disse: "Estão verdes, não prestam,

Só os cães os podem tragar!"

Eis cai uma parra, quando

Prosseguia seu caminho,

E crendo que era algum bago,

Volta depressa o focinho.

(Fábulas de La Fontaine, p.127)

Seguindo o histórico do gênero, podemos dizer que a moral bem definida ou expressa literalmente vem de outro movimento discursivo, pois, utilizando a fábula como instrumento pedagógico, os antigos deixavam de lado a ação, o drama e a imagem para chegar diretamente ao alvo pretendido - a asserção moralizadora ou crítica. Para Portella (1983, p.123), na evolução do gênero "nota-se a inversão da importância destes dois elementos: quanto mais se avança na história da fábula, mais se vê decrescer o caráter sentencioso e pedagógico em proveito da ação”. Sustentando essa caracterização, o autor apresenta um elemento essencial para uma definição da fábula como gênero - o caráter pedagógico:

\footnotetext{
Explicitado no começo ou no fim ou implícito no corpo da narrativa, é a moralidade que diferencia a fábula das formas narrativas próximas como o mito, a lenda e o conto popular. Sob o aspecto da moralidade, situa-se a fábula entre o provérbio e a anedota. O provérbio é só moralidade, ao passo que a anedota é só narrativa. A fábula contém ambos, sob o manto de uma alegoria (PORTELLA, 1983, p.123).
}

Essa constatação aponta para dois elementos centrais para o conceito de plano préformatado para um gênero que aqui defendemos, neste caso, para a fábula: a ideia de moralidade (ensinamento, lição de vida) e a ideia de sequência matriz narrativa com sequências encaixadas: argumentativa (para a avaliação/moral) e descritiva (para a situação inicial).

$\mathrm{Na}$ terceira ponta de nosso esquema, situamos o estilo, aqui delimitado e simplificado (mas não necessariamente limitado) como estilo de gênero nas formas prosa ou verso. Consideramos, nessa proposta, a análise do gênero fábula por um efeito de coletividade dos textos, ou seja, por uma visão global das fábulas ${ }^{9}$ em que há recorrência de temática, estilo e forma de composição. Trazendo o esquema de PPF para análise da questão, teríamos o seguinte:

\footnotetext{
${ }^{9}$ Nas leituras realizadas (COSTA, 2013; ROJO; BARBOSA, 2015) encontramos também a possibilidade analítica do efeito de individualidade do texto, ou seja, os aspectos únicos presentes em cada texto, marca também da heterogeneidade constitutiva dos textos.
} 
Figura 5 - PPF de gênero para a fábula

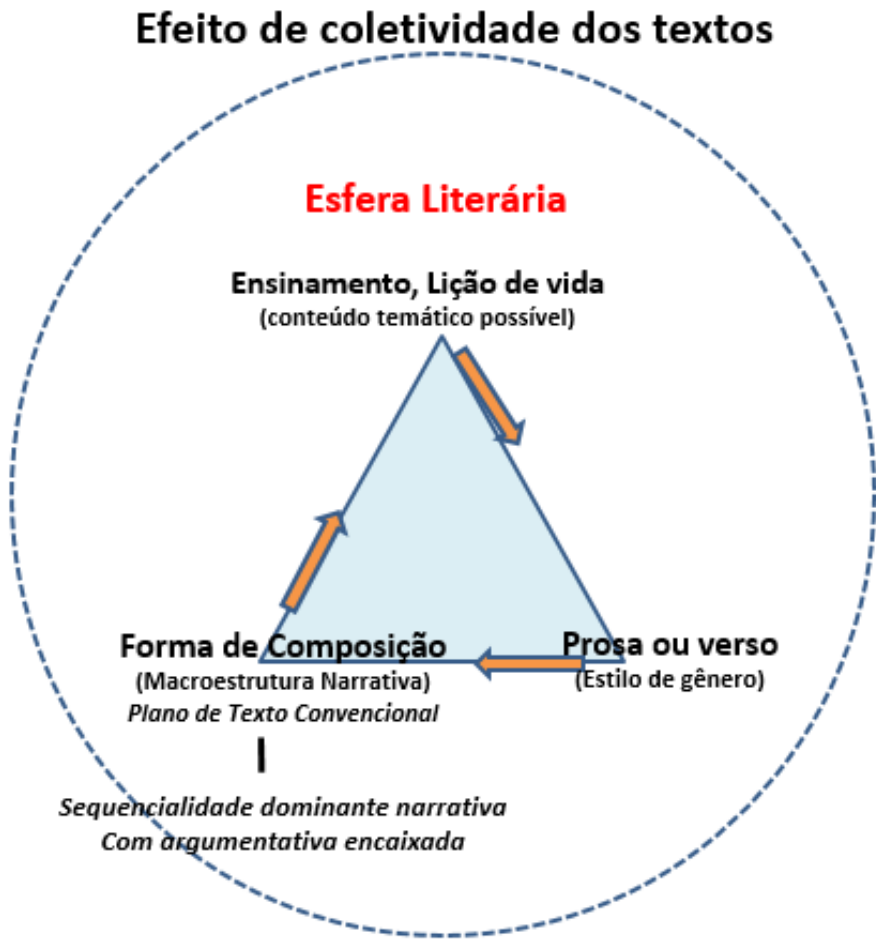

6 ALGUMAS CONSIDERAÇÕES FINAIS

Pelo discutido, mesmo que experimentalmente utilizando um pequeno grupo de textos dentro apenas de um domínio, o literário, observamos que a descrição do plano pré-formatado para um gênero pela tríade tema, composição e estilo permitiu reconhecer a existência de traços de recorrência convencionados. Para esse gênero em particular, a sequência narrativa e a moral (sequência argumentativa inserida) seriam, para Portella (1983), o que La Fontaine afirma ser o corpo e a alma desse gênero. Esses dois aspectos que tratam em si da forma e do tema do gênero são fundamentais para o seu PPF, que permanece na memória cultural da sociedade. Quanto ao estilo, apesar de termos citado no esquema apenas a disposição prosa/verso como estilos para o gênero - embasados no estudo exaustivo de gênero realizado por Portella (1983) -, outros elementos linguísticos poderiam também ser apresentados, como seu caráter alegórico, irônico, comparativo ou de parábola com base na evocação de outra realidade, etc., o que poderia ser facilmente caracterizado como uma dimensão social do estilo (COSTA, 2013).

Os três traços (estilo, forma, tema) anteriormente expostos compõem juntos um conjunto de características mais ou menos esperáveis, previsíveis de um gênero, por isso chamaríamos de plano pré-formatado para um gênero, sem, necessariamente, vinculá-lo a um plano puramente textual, quanto à sequencialidade. Tais aspectos são relevantes, pois poderiam estender esses princípios analíticos a outros gêneros. Não descartamos, por outro lado, os traços únicos de cada exemplar de texto - efeito de individualidade dos textos, ou plano de texto ocasional -, contudo nosso objetivo não era descrever os aspectos singulares de um exemplar de gênero. 
ADAM, J. -M. Les Textes: types et prototypes - récit, description, argumentation, explication et dialogue. Paris: Nathan Université, 1997.

Período. In: CHARAUDEAU, P.; MAINGUENEAU, D. Dicionário de Análise do Discurso. São Paulo: Contexto, 2008. p. 373.

. A Linguística textual. Introdução à análise textual dos discursos. São Paulo: Cortez, 2011.

Analyse textuelle des discours: niveaux ou plans d'analyse. Revista Filologia e Linguística Portuguesa, São Paulo, v.14, n. 2, p.191-202, 2012.

Les Textes: types et prototypes. Paris: Armand Colin, 2017.

; BONHOMME, M. L'argumentation publicitaire: Rhétorique de l'éloge et de la persuasion. Paris: Armand Colin, 2010.

BAKHTIN, M. Os gêneros do discurso. In: Estética da criação verbal. São Paulo: Martins Fontes, 1997.

CATELÃO, E. M. Revelando motivos: a argumentação suicida sob as perspectivas textual/discursiva e retórica. 2013. Tese (Doutorado em Letras) - Programa de Pós-graduação em Letras, Universidade Federal do Paraná, Curitiba, 2013.

COSTA, I. B. Gênero e estilo. Revista Letras, Curitiba, n. 88, p.151-169, jul./dez. 2013.

JURACH, J.M. O domínio dos acadêmicos de letras sobre a análise linguística em gêneros textuais. 2015. 247 f. Tese (Doutorado em Letras) - Programa de Pós-Graduação em Letras, Universidade Federal do Paraná, Curitiba, 2015.

LA FONTAINE, J. Fábulas, v.1. São Paulo: Egéria, 1981.

MARCUSCHI, L. A. Gêneros Textuais: definição e funcionalidade. In: DIONISIO, A. P.; MACHADO, A. R. Gêneros textuais e ensino. Rio de Janeiro: Lucerna, 2005. p.19-36.

Produção textual, análise de gênero e compreensão. São Paulo: Parábola, 2008.

PORTELLA, O.O. A fábula. Revista Letras, Curitiba, v. 32, p.119-138, 1983.

ROJO, R.; BARBOSA, J. P. Hipermodernidade, multiletramentos e gêneros discursivos. São Paulo: Parábola, 2015.

VOLOCHINOV, V. N.; BAKHTIN, M. M. Marxismo e filosofia da linguagem. São Paulo: Hucitec, 1981.

WACHOWICZ, T. C. Análise linguística nos gêneros textuais. Curitiba: IBPEX, 2010.

Recebido em: 14/03/17. Aprovado em: 20/09/17.

Title: Preformatted plan for a genre

Authors: Evandro de Melo Catelão; Mônica Magalhães Cavalcante

Abstract: The notion of text plan (PT) is re-discussed in this study and brings considerations that contribute to the forms of characterization of the PT in analysis of genre in more stable formats. Our reflections (theoretical/methodological) focused on what could distinguish, by another look, a fixed PT (PTF) and an occasional PT (PTO). We asked whether it would be more appropriate to verify the prototypical dominance of the genre, treating it as a preformatted plan (PPF). Thereunto, we retake the analysis of sequential connections made by Adam (2011; 2017), using fables as examples. Data from the analysis allowed the determination of a tool, more comprehensive in terms of prototypical recognition, reinforcing our hypothesis that the notion of PT has brought relation with the compositional nature of genre. The observation of the corpus by PPF allowed obtaining a scheme that contemplates the three elements that characterize the genres (theme, style and composition form).

Key words: Textual/discursive analysis. Text plan. Pre-formatted plan. Fable. 
Título: Plan pre formateado para un género

Autores: Evandro de Melo Catelão; Mônica Magalhães Cavalcante

Resumen: La noción de plan de texto (PT) es rediscutida en este estudio con el objetivo de proponer consideraciones que contribuam para las formas de caracterización de los PT en análisis de géneros de formatos más estables. Nuestras reflexiones (teórico/metodológicas) inciden sobre lo que podría diferenciar, por medio de otra mirada, un PT fijo (PTF) y un PT ocasional (PTO). Preguntamos si no sería más apropiado verificar la dominancia prototípica del género, tratándola como un plan pre formateado (PPF). Para ello, retomamos los análisis de ligaciones secuenciales realizadas por Adam (2011; 2017), usando fabulas cómo ejemplo. Datos del análisis permitieron la determinación de una herramienta más completa en términos de reconocimiento de la cualidad de prototipo, reforzando nuestra hipótesis de que la noción de PT tiene amplia relación con la naturaleza composicional de los géneros. La observación del corpus por medio del PPF posibilitó obtener un trazado que comporta los tres elementos que caracterizan los géneros (tema, estilo y forma de composición).

Palabras-clave: Análisis textual/discursivo. Plan de texto. Plan pre formateado. Fábula.

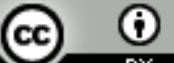

Este texto está licenciado com uma Licença Creative Commons Atribuição 4.0 Internacional. 